\title{
Formação de terapeutas comunitários na Paraíba: impacto na Estratégia Saúde da Família
}

\author{
The preparation of community therapists in Paraiba: the effect on the Family Health Strategy
}

Capacitación de terapeutas comunitarios en Paraiba: impacto en la Estrategia Salud de la Familia

Mayra Helen Menezes Araruna ${ }^{1}$, Maria de Oliveira Ferreira Filha², Maria Djair Dias³, Lucineide Alves Vieira Braga Marina Nascimento de Moraes ${ }^{5}$, lanine Alves da Rocha ${ }^{6}$

\section{RESUMO}

A Terapia Comunitária Integrativa - TCl - chegou à Atenção Básica de Saúde por meio de convênio entre Ministério da Saúde e Universidade Federal do Ceará, mediada pelo Movimento Integrado de Saúde Mental Comunitária/Ceará, tendo participação ainda do Pólo Formador Movimento Integrado de Saúde Comunitária/Paraíba. Este trabalho teve como objetivo caracterizar o perfil profissiográfico dos terapeutas formados na Paraíba e revelar as contribuições da formação. Estudo documental, compreensivo e interpretativo, foi realizado no acervo do Pólo Paraíba. Os dados foram analisados quantitativa e qualitativamente à luz da literatura pertinente. Formaram-se 277 terapeutas, predominando 248 mulheres e 99 Agentes Comunitários de Saúde. As contribuições foram analisadas em três aspectos: pessoal, trabalho em equipe e comunidade. Verificou-se um aumento da autoestima dos profissionais, melhoria de relacionamento com a equipe e fortalecimento do vínculo com a comunidade. A TCl viabilizou processos de mudança, sendo uma ferramenta apropriada para o trabalho comunitário na Estratégia Saúde da Família.

Descritores: Terapia; Formação de Recursos Humanos; Saúde da Família.

\section{ABSTRACT}

The Integrative Community Therapy - IGT - reached Primary Health Care by means of an agreement established between the Ministry of Health and Universidade Federal do Ceará, mediated by Movimento Integrado de Saúde Mental Comunitária/Ceará, also counting with the participation of Pólo Formador Movimento Integrado de Saúde Comunitária/Paraíba. The objective of this study was to characterize the professional competence profile of the therapists prepared in Paraíba, and reveal the contributions of their preparation. This documental, comprehensive and interpretative study was performed the data obtained from Pólo Paraíba. The data were subjected to quantitative and qualitative analyses under the light of pertinent literature. A total of 277 therapists were prepared, most of which were women (248), in addition to 99 Community Health Agents. The contributions were analyzed considering three aspects: personal, teamwork and community. It was verified there was an improvement in the workers' selfesteem, an improvement of the relationship with the team, and their attachment with the community was strengthened. The IGT promoted change processes, and is an appropriate tool for community work in the Family Health Strategy.

Descriptors: Therapy; Human Resources Formation,;Family Health.

\section{RESUMEN}

La Terapia Comunitaria Integrativa (TCl) llegó a la Atención Básica de Salud mediante convenios entre el Ministerio de Salud y la Universidad Federal de Ceará, intercedido por Polo Formador Movimiento Integrado de Salud Mental Comunitaria/Ceará, participando también Polo Formador Movimiento Integrado de Salud Comunitaria/Paraíba. El trabajo objetivó caracterizar el perfil profesiográfico de los terapeutas formados en Paraíba y revelar las contribuciones de la formación. Estudio documental, comprensivo e interpretativo, realizado en el acervo del Polo Paraíba. Datos analizados cuantitativa y cualitativamente frente a literatura pertinente. Se formaron 277 terapeutas, predominando 248 mujeres y 99 Agentes Comunitarios de Salud. Las contribuciones se analizaron bajo tres aspectos: personal, trabajo en equipo y comunidad. Se verificó aumento de autoestima de profesionales, mejora de relación con el equipo y fortalecimiento del vínculo comunitario. La TCl viabilizó procesos de cambio, constituyéndose en herramienta apropiada para el trabajo comunitario en la Estrategia Salud de la Familia.

Descriptores: Terapia; Formación de Recursos Humanos; Salud de La Familia.

\footnotetext{
1 Enfermeira. João Pessoa, PB, Brasil. E-mail: mayra menezes @hotmail.com.

2 Enfermeira, Doutora em Enfermagem, Professora Adjunto, Universidade Federal da Paraíba (UFPB). João Pessoa, PB, Brasil. E-mail: marfilha@yahoo.com.br.

${ }_{3}$ Enfermeira, Doutora em Enfermagem, Professora Adjunto, UFPB. João Pessoa, PB, Brasil. E-mail: mariadjair@yahoo.com.br.

${ }^{4}$ Enfermeira, Mestre em Enfermagem, Professora, Centro Universitário de João Pessoa e Faculdade de Ciências Médicas de João Pessoa. João

Pessoa, PB, Brasil. E-mail: lucineide.avb@gmail.com.

${ }^{5}$ Enfermeira. João Pessoa, PB, Brasil. E-mail: ninamoraes_@hotmail.com.

${ }^{6}$ Enfermeira, Discente do Programa de Pós-Graduação em Enfermagem, UFPB. João Pessoa, PB, Brasil. E-mail: ian ine@yahoo.com.br.
} 


\section{INTRODUÇÃO}

A Organização Mundial de Saúde (OMS) e a Organização Pan-americana de Saúde (OPS) têm considerado a saúde mental uma prioridade que deve ser assumida pelos governos latino-americanos, uma vez que, apesar do aumento ostensivo dos sofrimentos psíquicos, a maioria deles é prevenível(1).

Estimativas da OPS e OMS para a magnitude dos problemas mentais, dentro de 25 anos, esperam que a cada quatro habitantes do planeta, um enfrentará algum tipo de transtorno mental. A carga global de transtornos mentais no mundo indicam os problemas mentais com $8,1 \%$, dentre eles, os transtornos depressivos estão no topo com $17,3 \%$, seguido de demências e doença de Alzheimer com 12,7\%, dependência de álcool com 12,1\%, entre outros ${ }^{(2)}$.

A partir da década de 1990, a rede do Sistema Único de Saúde (SUS) vem organizando seu serviço em níveis de complexidade, sendo eles, Atenção Básica (AB), média e alta complexidade. Contudo, há uma desintegração entre esses níveis de cuidado, bem como a sobreposição de ações nos serviços de média e alta complexidade. Na saúde mental fica evidente, ainda, a falta de cuidados nos serviços de $A B^{(2)}$.

Desde o início da implantação da Estratégia Saúde da Família (ESF), então denominado Programa de Saúde da Família, em João Pessoa-PB no ano de 1996, observase uma ampliação na rede de cuidados primários de saúde. Porém, $90 \%$ dos profissionais que compõem às equipes saúde da família ainda não se sentem preparados para atender a demanda de usuários com sofrimento psíquico e desconhecem modos de abordagem a tais pessoas ${ }^{(3)}$.

A implantação da Terapia Comunitária Integrativa (TCl) na ESF visa o preenchimento de lacunas como essas, na assistência à saúde das comunidades, por meio do apoio às atividades associativas, combate ao isolamento, promoção da reinserção social e estímulo às capacidades dos indivíduos para enfrentar os problemas do cotidiano ${ }^{(4)}$.

A utilização dessa ferramenta no cuidado à saúde mental da comunidade acompanha a mudança de uma política assistencialista para uma de participação solidária, centradas na promoção da saúde e no desenvolvimento comunitário e social da população(4). Dessa maneira, a $\mathrm{TCl}$ constitui um espaço de escuta, reflexão e troca de experiências ${ }^{(5)}$. Propõe ser um instrumento de aquecimento e fortalecimento das relações humanas, em que cada um torna-se terapeuta de si mesmo, e coletivamente formem redes solidárias de fortalecimento da autoestima de pessoas, famílias e comunidades, de onde a mudança decorre ${ }^{(6)}$.

Vale lembrar ainda, que as ações da Terapia Comunitária Integrativa se encontram em consonância com as ações propostas no Pacto pela Saúde, Ministério da Saúde (MS), em 2006, que consiste em um pacto solidário para que o usuário seja atendido em princípios de equidade, universalidade e integralidade. A finalidade deste pacto é prover meios de promoção à saúde na atenção básica ${ }^{(7)}$.

A necessidade de se ampliar modelos de atenção à saúde comunitária nos faz pensar na Terapia Comunitária Integrativa como tecnologia a ser implantada nos serviços de atenção básica, uma vez que a $\mathrm{TCl}$ se utiliza de uma metodologia horizontal e circular para o acolhimento, a partilha de sofrimentos e troca de experiências ${ }^{(6)}$.

Este estudo torna-se relevante, pois a $\mathrm{TCl}$ vem expandindo-se para outras realidades, nacionais e internacionais. O Ministério da saúde em parceria com a Universidade Federal do Ceará - UFC vem promovendo cursos de formação em Terapia Comunitária. Em 2008, o convênio abrangeu a formação de 1.050 terapeutas em território nacional, buscando incluir a $\mathrm{TCl}$ na atenção básica de saúde, por meio das Equipes de Saúde da Família, devido, principalmente, as repercussões positivas desta ferramenta. No ano de 2009 o convênio foi renovado com o Ministério e mais 950 terapeutas estão sendo formados, espalhados pelo território nacional. É importante mencionar que o Pólo de Formação Movimento Integrado de Saúde Comunitária MISC/PB vem participando ativamente deste processo de formação, como atividade de extensão do Grupo de Estudos e Pesquisa em Saúde Mental Comunitária.

O Pólo Formador em Terapia Comunitária Integrativa MISC/PB tem investido na formação de terapeutas comunitários para a rede do SUS, especificamente para a atenção básica em saúde, em municípios paraibanos a exemplo de: João Pessoa, Pedras de Fogo, Conde, São Bento, Patos, Itaporanga, Piancó, Princesa Isabel, Catingueira, Mãe D'Água (2007 a 2009) e mais recentemente nos municípios de Sousa, Cajazeiras, Santa Luzia, Bonito de Santa Fé, Pombal, 
Uiraúna e Campina Grande, além de Pau dos Ferros/RN (2009 a 2010).

Uma busca a literatura revisando aspectos que envolvem a Terapia Comunitária Integrativa mostraram um avanço desta ferramenta no contexto da $A B$, evidenciado pela ampliação nos cursos de formação, que abrangem todas as regiões brasileiras, envolvendo atualmente 16 Estados e 120 municípios. Esses dados sinalizam boa cobertura, oportunizando o acesso da comunidade a esta abordagem de atenção comunitária em saúde. Desde o primeiro convênio firmado entre a UFC e a Secretaria Nacional de Políticas sobre Drogas (SENAD), a TCl mostra impacto na ESF, em que $88,5 \%$ dos casos atendidos encontravam acolhimento na própria $\mathrm{TCl}$, e somente $11,5 \%$ necessitavam encaminhamento para outro serviço ${ }^{(8)}$.

O processo de formação em Terapia Comunitária Integrativa permite compreender o mecanismo do trabalhador em desenvolver a capacidade de autoconhecimento, para que ele possa atuar no mundo do trabalho sem escravizar-se nem alienar-se, tornandose um mero insumo, no processo de trabalho. Ao se deparar com o outro, usuário do serviço, o trabalhador necessita estabelecer uma relação comunicacional efetiva e afetiva, para dar sentido a sua práxis. Sem sentido algum, o trabalho fica vazio, inútil; o trabalhador, por sua vez sente-se desmotivado e sem energia para efetuar mudanças.

As questões que nortearam este estudo foram: Qual o perfil profissiográfico dos terapeutas comunitários formados? Quais as contribuições que a formação em terapia comunitária trouxe para a vida pessoal e profissional dos terapeutas na ESF? Assim, esta investigação teve o objetivo de caracterizar o perfil profissiográfico dos terapeutas formados pelo MISC/PB, e identificar as contribuições que a formação em terapia comunitária trouxe para a vida pessoal e profissional dos terapeutas na ESF.

Tendo em vista a inserção da $\mathrm{TCl}$ na ESF e a ampliação do curso de formação de terapeutas comunitários por meio dos Pólos Formadores pelo Brasil, considerando também sua expansão pela América Latina, é de fundamental importância avaliar de que maneira estão sendo realizados tais cursos, preservando a qualidade das ações propostas. Nesse sentido buscar a visão dos terapeutas ainda em processo de formação, é uma forma de identificar como o curso proporciona mudanças, e se estas são de fato positivas para o cursista e sua atividade profissional desenvolvida, assim como para sua relação com a comunidade. Essa investigação possibilita direcionar um olhar para necessidades específicas, a fim de formar terapeutas comprometidos.

\section{METODOLOGIA}

O presente estudo encontra-se vinculado a um projeto maior intitulado: "A formação de terapeutas comunitários: um novo caminho para a saúde mental", coordenado por docentes do Programa de PósGraduação em Enfermagem e do Departamento de Enfermagem em Saúde Pública e Psiquiatria da Universidade Federal da Paraíba (UFPB), inserido na linha de pesquisa Política e Práticas em Saúde e Enfermagem.

Trata-se de um estudo do tipo documental, compreensivo e interpretativo. Documental porque utiliza documentos originais, que não receberam tratamento analítico por nenhum autor ${ }^{(9)}$. É compreensivo e interpretativo, pois através da compreensão torna-se possível interpretar os valores envolvidos e motivadores das ações humanas(10). Foram utilizadas as abordagens quantitativa e qualitativa devido a especificidade do objeto. Porém, não trabalhamos com variáveis, pois não pretendíamos fazer correlação.

A pesquisa foi realizada no acervo documental do Pólo MISC/PB, na Universidade Federal da Paraíba, município de João Pessoa, Estado da Paraíba. O local dispõe dos registros documentais do processo de formação em Terapia Comunitária Integrativa, necessários para realização da pesquisa, o que viabilizou o estudo proposto.

Em pesquisa documental, o objeto de investigação é o documento. Entende-se documento como fontes de informações que trazem seu conteúdo para elucidar determinadas questões, constituindo-se a fonte primária.

Foram analisadas 1.830 documentos no período de setembro de 2010 a maio de 2011. Os documentos utilizados no presente estudo são em forma de texto escrito, ou seja, foram utilizadas as fichas de registro das rodas de $\mathrm{TCl}$ realizadas pelos terapeutas em formação, relatórios de módulos e intervisões, fichas cadastrais, além de questionários, respondidos pelos cursistas, aplicados durante a realização da quinta turma de formação em TCl, em 2010, correspondente a uma 
avaliação proposta no programa do curso, a fim de investigar as repercussões desta formação no campo pessoal e profissional dos terapeutas, e no vínculo com a comunidade, por meio de relatos de vivências pessoais. Buscou-se os documentos arquivados no Pólo de Formação MISC/PB após autorização pela coordenadora do Pólo, mediante assinatura do Termo de Risco e Confidencialidade.

Os registros foram separados em pastas individuais organizadas pelo próprio terapeuta, de acordo com o seu município. A primeira etapa da pesquisa consistiu na consulta dessas pastas dos terapeutas formados e dos que ainda estavam em processo de formação das turmas do sertão paraibano, para ser, posteriormente avaliado em função da qualidade da informação prestada, tendo em vista os objetivos a serem alcançados. Após seleção do material empírico documental, foi organizado um banco de dados para posterior análise do mesmo.

A análise dos achados da pesquisa consistiu em dar forma e sentido às respostas encontradas, de maneira precisa e imparcial. O material foi analisado quanti e qualitativamente à luz da literatura pertinente. Os dados quantitativos foram tratados por meio de estatística descritiva para evidenciar o coletivo estudado.

Рага a compreensão das informações encontradas nos registros dos terapeutas, a análise qualitativa foi realizada seguindo-se as seguintes etapas: seleção e análise geral do documento; análise do conteúdo, observando a frequência da citação de termos, palavras ou ideias; registro, através de anotações, esquemas, diagramas, entre outros; montagem de categorias de análise, agrupando as informações a partir de aspectos que apareçam com regularidade; e aprofundamento, ligação e ampliação, momento em que retorna-se às categorias buscando novos ângulos e aprofundando a visão.

Este estudo atende aos requisitos propostos pela Resolução 196/96, que dispõe sobre as normas e diretrizes regulamentadoras da pesquisa envolvendo os seres humanos, respeitando o Código de Ética dos Profissionais de Enfermagem, e assegura os direitos e deveres que dizem respeito à comunidade científica, aos sujeitos das pesquisas e ao Estado. A pesquisa teve início após o projeto ter sido encaminhado e aprovado pelo Departamento de Enfermagem em Saúde Pública e Psiquiatria e posteriormente submetido ao Comitê de Ética e Pesquisa do Hospital Universitário Lauro
Wanderley (HULW), do qual obteve parecer favorável, com protocolo $n^{\circ} 739 / 10$.

\section{RESULTADOS E DISCUSSÃO}

\section{Perfil do Terapeuta Comunitário}

Na Paraíba foram formados 277 terapeutas comunitários, em cinco turmas, sendo as duas primeiras organizadas pelo Instituto Brasileiro de Desenvolvimento da Pessoa Humana (IBDPH) em parceria com a Universidade Federal de Paraíba (UFPB), a Secretaria Municipal de Saúde (SMS) de João Pessoa-PB (primeira turma), e Secretaria Municipal de Saúde de Pedras de Fogo (segunda turma), ambas no ano de 2007. A UFPB teve um papel de colaborador nas duas turmas, que contou com a participação de docentes com formação em multiplicadores de Terapeutas Comunitários.

A SMS de João Pessoa a partir da gestão municipal de 2005 buscou priorizar a produção do cuidado integral, humanizado e de qualidade. Junto a isso, adota as diretrizes da Educação Permanente, o Matriciamento e o Acolhimento como estratégia para alcançar os objetivos. Nesse contexto, a SMS reconhece a Terapia Comunitária Integrativa como dispositivo potencial de cuidado em Saúde Mental na Atenção Básica.

Apenas em 2008, a formação passou a ser realizada pelo Pólo de Formação em Terapia Comunitária Integrativa, o Movimento Integrado de Saúde Comunitária da Paraíba - MISC/PB. Neste ano foram desenvolvidas a terceira e quarta turmas de formação, lembrando que foram as primeiras turmas realizadas pelo Pólo MISC/PB já constituído.

A terceira turma resultou de uma parceria entre a SMS de João Pessoa e o MISC/PB. A quarta turma, por sua vez, teve a contribuição do Ministério da Saúde, Movimento Integrado de Saúde Mental Comunitária do Ceará - MISMEC/CE e MISC/PB, formando 57 terapeutas comunitários. Finalmente, a quinta turma contou com a mesma parceria organizadora da quarta turma e obteve 55 concluintes. Os resultados obtidos quanto ao perfil profissiográfico estão apresentados na tabela abaixo (Tabela 1). 
Tabela 1: Distribuição dos profissionais formados segundo as variáveis profissiográficas. João Pessoa, PB, 2010.

\begin{tabular}{|c|c|c|c|c|c|c|c|c|c|c|c|c|}
\hline \multirow[t]{2}{*}{ TURMA } & \multicolumn{2}{|c|}{ Primeira 2007} & \multicolumn{2}{|c|}{ Segunda 2007} & \multicolumn{2}{|c|}{ Terceira 2008} & \multicolumn{2}{|c|}{ Quarta 2008} & \multicolumn{2}{|c|}{ Quinta 2009} & \multicolumn{2}{|c|}{ TOTAL } \\
\hline & $\mathrm{N}^{\circ}$ & $\%$ & $\mathrm{~N}^{0}$ & $\%$ & $\mathbf{N}^{\circ}$ & $\%$ & $\mathbf{N}^{0}$ & $\%$ & $\mathbf{N}^{\circ}$ & $\%$ & $\mathrm{~N}^{\circ}$ & $\%$ \\
\hline$N^{0}$ terapeutas & 61 & 22 & 42 & 15 & 62 & 22 & 57 & 21 & 55 & 20 & 277 & 100 \\
\hline \multicolumn{13}{|l|}{ Sexo } \\
\hline Feminino & 53 & 87 & 37 & 87 & 57 & 92 & 51 & 89 & 50 & 91 & 248 & 90 \\
\hline Masculino & 8 & 13 & 5 & 13 & 5 & 8 & 6 & 11 & 5 & 9 & 29 & 10 \\
\hline \multicolumn{13}{|l|}{ Faixa etária } \\
\hline 21 a 39 anos & 30 & 49 & 15 & 36 & 26 & 42 & 46 & 81 & 37 & 67 & 154 & 56 \\
\hline 40 a 59 anos & 25 & 41 & 16 & 38 & 36 & 58 & 10 & 17 & 18 & 33 & 105 & 38 \\
\hline 60 ou mais & 1 & 2 & 2 & 5 & - & - & 1 & 2 & - & - & 4 & 1 \\
\hline s/ resposta & 5 & 8 & 9 & 21 & - & - & - & - & - & - & 14 & 5 \\
\hline \multicolumn{13}{|l|}{ Profissão } \\
\hline Enfermeiros & 27 & 44 & 10 & 24 & 21 & 34 & 16 & 28 & 19 & 35 & 93 & 34 \\
\hline Médicos & 3 & 5 & 8 & 19 & 2 & 3 & 1 & 2 & 1 & 2 & 15 & 5 \\
\hline Dentistas & 4 & 7 & - & - & 8 & 13 & 3 & 5 & 1 & 2 & 16 & 6 \\
\hline Téc. Enf. & 2 & 3 & - & - & 3 & 5 & - & - & 3 & 5 & 8 & 3 \\
\hline $\mathrm{ACD}$ & 1 & 2 & - & - & - & - & - & - & - & - & 1 & 0,5 \\
\hline ACS & 13 & 22 & 9 & 21 & 16 & 26 & 34 & 60 & 27 & 49 & 99 & 36 \\
\hline Fisioterapeuta & 2 & 3 & - & - & 2 & 3 & - & - & 1 & 2 & 5 & 2 \\
\hline Farmacêutico & 2 & 2 & - & - & - & - & - & - & - & - & 2 & 1 \\
\hline Psicólogo & 4 & 7 & - & - & 5 & 8 & 2 & 3 & 1 & 2 & 12 & 4 \\
\hline Educador & 3 & 5 & - & - & 3 & 5 & - & - & 1 & 1 & 7 & 2 \\
\hline Assist. Social & - & - & - & - & 2 & 3 & 1 & 2 & - & - & 3 & 1 \\
\hline Funcionário SMS & - & - & - & - & - & - & - & - & 1 & 2 & 1 & 0,5 \\
\hline Não especificado & - & - & 15 & 36 & & - & - & - & - & - & 15 & 5 \\
\hline \multicolumn{13}{|l|}{ Local de trabalho } \\
\hline SMS & 9 & 15 & 1 & 2 & 10 & 16 & 1 & 2 & 10 & 18 & 31 & 11 \\
\hline ESF & 36 & 59 & 26 & 62 & 52 & 84 & 52 & 91 & 44 & 80 & 210 & 76 \\
\hline CRAS & - & - & - & - & - & - & 3 & 5 & - & - & 3 & 1 \\
\hline Não especificado & 16 & 26 & 15 & 36 & - & - & 1 & 2 & 1 & 2 & 33 & 12 \\
\hline
\end{tabular}

Ao avaliar o perfil geral dos terapeutas comunitários, observamos que a primeira turma obteve uma representação significativa de enfermeiros e ACS, o que se manteve nas turmas subsequentes. Porém, 0 quantitativo dos ACS superou o dos enfermeiros, caracterizando o curso quanto à profissão/ ocupação com a predominância de ACS (36\%), seguido de enfermeiros (34\%).

Outro aspecto mostra a maioria feminina e faixa etária entre 20 e 39 anos, característica entre os terapeutas em formação. A participação majoritária de mulheres confirma a tendência que elas têm em exercer o papel do cuidado nas comunidades. Por sua vez, a adesão de jovens profissionais recém ingressos no Sistema Público de Saúde demonstra o interesse em participarem de ações complementares, tornando-se parceiros de uma política voltada a promoção da saúde ${ }^{(8)}$.

Fato correspondente à herança histórica que associa o cuidar às mulheres, que desde as sociedades antigas, eram responsáveis pelo cuidado de seus filhos e marido. A própria profissão de enfermagem, diretamente ligada ao cuidar, detém a maioria feminina, e obtém uma grande representação entre os terapeutas.

A TCl não exige uma formação acadêmica específica, para ser um terapeuta comunitário é necessário que o indivíduo possua, acima de tudo, vontade de adquirir novos conhecimentos e aplicá-los na comunidade na qual trabalha, melhorando a qualidade da assistência prestada(6).

Os dados correspondentes às turmas apresentadas revelam a prevalência dos Agentes Comunitários de Saúde e enfermeiros entre os cursistas. É relevante esclarecer que o MS determinou dois ACS para cada profissional da Estratégia Saúde da Família, para a quarta e quinta turma.

Os enfermeiros que trabalham na ESF se tornam grandes potencializadores para a realização das práticas de educação e promoção da saúde. Estão em contado direto e constante com a comunidade através de grupos e visitas, além dos atendimentos direcionados, através dos quais conhece as diversas situações estressantes que causam o adoecimento mental da população e juntos constroem e reforçam um vínculo importante para qualquer ação em saúde. Diante dessa situação o 
profissional se torna foco da formação em $\mathrm{TCl}$, pois, encontra-se sensibilizado com a realidade da comunidade, possibilitando o comprometimento de atuação utilizando a $\mathrm{TCl}$ como estratégia de promoção da saúde e prevenção do adoecimento.

Por sua vez, além da responsabilidade que tem ao trabalhar na ESF, o ACS faz parte da própria comunidade, e a formação em Terapia Comunitária Integrativa possibilita que ele trabalhe em prol da população que divide com ele a mesma realidade, promovendo e participando do resgate da identidade cultural de sua região. A $\mathrm{TCl}$ permite uma construção em duas vias, promove uma reflexão em que tanto terapeuta como participantes reavaliam as situações expostas com olhares diferentes, semeando uma mudança interna que será refletida em todos os aspectos de sua vida.

As equipes de saúde da família, em especial os agentes comunitários de saúde, que passam pela formação em TCl adquirem uma poderosa ferramenta de intervenção na comunidade, através da criação de grupos de Terapia Comunitária Integrativa, o que os possibilita identificar e atender as necessidades de saúde da população(4).

A possibilidade de avaliar o local de trabalho dos participantes torna possível a visualização da inserção da TCl no contexto da Estratégia Saúde da Família, cumprindo com o objetivo de capacitar novos terapeutas comunitários para atuarem, prioritariamente, a nível de Atenção Básica, na promoção da saúde e prevenção do adoecimento mental.
A Estratégia Saúde da Família se configura como uma proposta para dar conta do processo de reorganização da Atenção Básica, porém a organização do processo de trabalho dos profissionais aí inseridos, permanece distanciada do mundo das necessidades dos usuários. Fazem-se necessárias políticas públicas que promovam ações que garantam a saúde de acordo com particularidades de cada usuário, e não centralizar a assistência na doença. Alterar o modo como os trabalhadores de saúde se relacionam com os usuários é o caminho para cumprir os preceitos constitucionais que garantem o direito à saúde de todos os brasileiros(11).

\section{Avaliação dos Terapeutas quanto às contribuições do curso de formação em Terapia Comunitária}

O desenvolvimento das turmas e a preocupação em aperfeiçoar cada vez mais o curso, fomentaram a necessidade de se avaliar as contribuições da formação em TCl para a vida pessoal e profissional dos cursistas, dando ênfase ao trabalho em equipe e com a comunidade sob o ponto de vista dos próprios profissionais. A análise dos documentos permitiu sua organização nessas três dimensões.

O primeiro ponto da avaliação focalizou a solicitação feita aos terapeutas sobre as contribuições que a formação em terapia comunitária integrativa trouxe para seu desenvolvimento pessoal. Por se tratar de uma questão subjetiva, distribuímos as respostas em 10 eixos temáticos, de acordo com semelhança de sentido nas respostas.

Tabela 2: Distribuição das respostas relacionadas ao impacto pessoal por eixo temático. João Pessoa, PB, 2010.

\begin{tabular}{|c|c|c|}
\hline Eixo temático & Respostas relacionadas & $\%$ \\
\hline Valorização pessoal & $\begin{array}{l}\text { Autoestima; Autoconfiança; Autoconhecimento; conhecer seus limites; enxergar as } \\
\text { fraquezas; saber dizer "não"; Autocuidado; Auto respeito; segurança. }\end{array}$ & $32 \%$ \\
\hline Redução do estresse & $\begin{array}{c}\text { Mais paciência; menos impulsivo/ explosivo; menos preconceito; tolerância; } \\
\text { tranqüilidade; serenidade; concentração. }\end{array}$ & $13 \%$ \\
\hline Cuidado & Ouvir mais/ escuta qualificada; não aconselhar; mais atenção para com as pessoas. & $11 \%$ \\
\hline $\begin{array}{l}\text { Relacionamentos } \\
\text { interpessoais }\end{array}$ & $\begin{array}{l}\text { Melhorar relacionamento com a família; fortalecimento dos valores pessoais; } \\
\text { espontaneidade; trabalhar a timidez. }\end{array}$ & $10 \%$ \\
\hline Capacidade & Encontro com a criança; empoderamento; força interior; aprender a lidar com conflitos. & $8 \%$ \\
\hline Percepção & Sensibilidade; compreensão/ compreender o outro; ser justo; perdoar. & $8 \%$ \\
\hline Valorização cultural & Valorização do passado; vínculo entre presente e passado. & $6 \%$ \\
\hline Esforço pessoal & Determinação; motivação; perseverança; lutar pelos objetivos. & $4 \%$ \\
\hline Satisfação no trabalho & $\begin{array}{l}\text { Prazer em trabalhar; agilidade e resolutividade no trabalho; Desejo de viver e trabalhar; } \\
\text { organização. }\end{array}$ & $4 \%$ \\
\hline Confiança no outro & Confiar mais nas pessoas; abrir-se mais com as pessoas; partilhar os sentimentos. & $4 \%$ \\
\hline
\end{tabular}

O terapeuta comunitário está voltado para a prevenção, mediação de crises e promoção da inserção social dos indivíduos. Por esta razão, é necessário que seja sensibilizado a lidar com suas próprias emoções, inseguranças e sofrimentos ajudando-o a conhecer suas limitações, para que assim saiba assumir a distância 
necessária entre suas emoções e as que surgem em cada terapia. Este conhecimento é alvo do curso e mostra resultados positivos no que os terapeutas relatam como impacto o autoconhecimento, autoestima, autoconfiança, categorizando a valorização pessoal.

A valorização pessoal, em destaque no impacto que o curso de formação em terapia comunitária trouxe para a vida do terapeuta, ocorre como consequência da crença do indivíduo, enquanto sujeito do processo de vida, como pertença ao grupo social diante da aceitação das diferenças individuais, resultando em valorização de cada indivíduo e respeito ao conviver com a diversidade ${ }^{(12)}$.

A terapia contribui para a melhoria da autoestima e resiliência, ou seja, tem-se a capacidade de adaptar-se e superar as situações difíceis, evidenciando em suas habilidades e competências, como autoconfiança(13). Cada um detém a chave do próprio sucesso ou fracasso ${ }^{(6)}$. Autoestima é o conjunto de atitudes que cada pessoa tem sobre si mesma, uma percepção avaliativa sobre si próprio, uma maneira de ser, segundo a qual a própria pessoa tem ideias sobre si mesmo, que podem ser positivas ou negativas. Não é estática, pois apresenta altos e baixos, revelando-se nos acontecimentos sociais, emocionais e psíquico-fisiológicos. O autoconhecimento é construção-desconstrução paulatina e cotidiana do reconhecimento dos limites pessoais e exteriores. Já a autoconfiança se fundamenta na autonomia e no autoconhecimento ${ }^{(14)}$.

A formação em Terapia Comunitária Integrativa ajuda na transformação pessoal e profissional através da maneira de se relacionar com as pessoas, tornando-se mais sensível aos problemas que afetam a sociedade. Sentir a dor do outro promove uma ação reativa, procuramos cuidar de quem sofre, e é a partir do cuidado com o outro que o ser humano desenvolve a dimensão da alteridade, do respeito e valores fundamentais da experiência humana ${ }^{(15)}$.

O segunda dimensão analisada nos documentos referiu-se às contribuições causadas pela formação em TC para o trabalho em equipe. Utilizamos a mesma técnica do item anterior, reagrupando as respostas de acordo com que eram citadas (Tabela 3 ).

Tabela 3: Distribuição das respostas relacionadas ao impacto no trabalho em equipe por eixo temático. João Pessoa, PB, 2010.

\begin{tabular}{clc}
\hline Eixo temático & \multicolumn{1}{c}{ Respostas relacionadas } & \multicolumn{1}{c}{ \% } \\
\hline $\begin{array}{c}\text { Valorização pessoal } \\
\text { Relacionamento com a } \\
\text { equipe }\end{array}$ & $\begin{array}{l}\text { Autoestima; autoconfiança; autoconhecimento; segurança; liderança. } \\
\text { Melhorar relacionamento com a equipe; resolutividade dos problemas; vínculo entre os } \\
\text { terapeutas; ações conjuntas com os profissionais; trabalho em equipe; organização. }\end{array}$ & $19 \%$ \\
Humanização & $\begin{array}{l}\text { Visão holística do indivíduo; trabalho humanizado; compreender o outro; valorizar o } \\
\text { sentimento do outro; cliente como um ser independente; ser mais justo, não julgar. }\end{array}$ & $18 \%$ \\
Redução do estresse & Paciência; aceitar as diferenças; controle da ansiedade; discernimento; sabedoria. & $13 \%$ \\
Cuidado & Escuta qualificada; comunicação; solidariedade. & $12 \%$ \\
Satisfação & Estímulo; participação; envolvimento; comprometimento; dinamismo; flexibilidade. & $10 \%$ \\
$\begin{array}{c}\text { Esforço pessoal } \\
\text { Fortalecimento do } \\
\text { vínculo }\end{array}$ & Determinação; Perseverança; superação. & $5 \%$ \\
\hline
\end{tabular}

O profissional que não está satisfeito com o trabalho que assume, não se sente estimulado a desempenhar suas funções, comprometendo a eficácia de suas ações. As mudanças proporcionadas pelo curso alcançam o íntimo do indivíduo e daí parte as repercussões no trabalho, na família e comunidade.

Por este motivo que, mesmo ao serem questionados sobre o impacto no trabalho em equipe, as respostas mostram primeiramente a valorização pessoal. Dessa forma, é fundamental que o profissional alcance esse estado, para que então possa melhorar seu relacionamento com os colegas de trabalho e adotar práticas diferenciadas na sua rotina.
Qualquer processo de mudança nos atores da atenção básica provoca impacto na sua atuação, modificando a assistência prestada à comunidade. A partir dos resultados visualizados, podemos observar que a formação promove uma mudança interna, consistente e amadurecida, que inevitavelmente impacta na sua relação com o outro, seja usuário da ESF ou colega de equipe, culminando na sintonia necessária para uma prática diferenciada.

O profissional sensibilizado e comprometido com a $\mathrm{TCl}$, a utiliza para maximizar e universalizar instrumentos que levam à prevenção dos problemas e das doenças psíquicas, somatizações, violência ou situações de crise 
familiar e intracomunitária cada vez mais presentes na nossa sociedade. Na rede pública, a TCl cria um cinturão de atenção, cuidado e prevenção, ser multiplicador do atendimento, identificar as situações graves e encaminhar aos centros especializados, atuando como um elo, além de favorecer o envolvimento multiprofissional da rede, que se configura uma proposta de atenção básica em saúde(16).

Finalmente, analisamos nos documentos as contribuições que a formação em TCl trouxe para o trabalho com a comunidade, a qual permitiu a organização dos dados em oito eixos temáticos.

Tabela 4: Distribuição das respostas relacionadas ao impacto no trabalho com a comunidade por eixo temático. João Pessoa, PB, 2010.

\begin{tabular}{|c|c|c|}
\hline Eixo temático & Respostas relacionadas & $\%$ \\
\hline $\begin{array}{l}\text { Fortalecimento do } \\
\text { vínculo }\end{array}$ & $\begin{array}{l}\text { Sentimento de pertença; integração; aproximação com a comuniadade; amizade/ } \\
\text { convivência; empoderamento da comunidade; união; união de diferentes grupos. }\end{array}$ & $28 \%$ \\
\hline Valorização pessoal & Confiança/ autoconfiança; segurança; paciência. & $17 \%$ \\
\hline Humanização & $\begin{array}{c}\text { Respeito aos sentimentos da comunidade; visão holística; acolhimento; ser justa; } \\
\text { compreensão. }\end{array}$ & $14 \%$ \\
\hline Cuidado & Escuta qualificada; solidariedade; diálogo; apoio. & $13 \%$ \\
\hline Trabalho em equipe & $\begin{array}{l}\text { Atividades extra USF; integração da equipe; credibilidade; novas estratégias; saber popular } \\
\text { e ciência; trabalho em equipe; planejamento; resolução de problemas. }\end{array}$ & $10 \%$ \\
\hline Esforço pessoal & Determinação; superação; perseverança; aprendizado. & $6 \%$ \\
\hline Responsabilização & $\begin{array}{c}\text { Responsabilidade; compromisso; reconhecimento; participação; identificação; objetividade } \\
\text { e clareza. }\end{array}$ & $6 \%$ \\
\hline Satisfação & Satisfação dos usuários; comunidade se conhece; otimismo; estímulo; realidade. & $6 \%$ \\
\hline
\end{tabular}

O vínculo remete a algo que liga pessoas, à interdependência, ao compromisso do profissional com seus pacientes e destes com o profissional. A construção e fortalecimento de vínculo se constituem um recurso terapêutico. A implantação da $\mathrm{TCl}$, enquanto tecnologia leve do cuidado é recomendada como potencializadora da construção de vínculo no serviço ${ }^{(17)}$.

O fortalecimento do vínculo gera a confiança necessária para que o profissional adentre na realidade do usuário da ESF, de forma a possibilitar a identificação sistemática da clientela, o reconhecimento precoce das manifestações de sofrimento mental e dependência química e a elaboração de estratégias de cuidado eficazes que propiciem a autonomia de todos os envolvidos $^{(18)}$.

A escuta, presente na categoria do cuidado é um ato fundamental na identificação das insatisfações e problemas pessoais de cada um, podendo criar a estrutura capaz de gerar aproximação e construção de vínculos. Aprender a ouvir antecede qualquer forma de aprendizagem. A TCl valoriza a escuta pois parte do pressuposto que toda pessoa possui recursos e saberes úteis aos outros, competências que provêm da superação das dificuldades e dos recursos culturais. Sob essa ótica, as partilhas ocorrem de forma circular e horizontal. A comunidade tem recursos para lidar com seus sofrimentos do cotidiano(8).
A Terapia Comunitária Integrativa atua como uma estratégia terapêutica centrada na potencialidade do indivíduo, proporcionando o equilíbrio mental, físico e espiritual, contrapondo-se a visão medicalizada anterior $^{(19)}$.

A política de saúde mental para atenção básica propõe uma associação às demais ações da $A B$, além de assegurar o bem estar da comunidade e do indivíduo; privilegiar ações preventivas, individuais e coletivas; alocar os programas em saúde mental em diferentes serviços da atenção primária, formando uma rede de suporte e cuidados; utilizar novas estratégias de abordagem em saúde; agregar profissionais com diferentes formações e considerar as características da comunidade $^{(20)}$. A TCl está inserida nas propostas de saúde coletiva, uma vez que procura promover a saúde em espaços coletivos, e não combater a patologia individualmente ${ }^{(8)}$.

Percebe-se então que a proposta da Terapia Comunitária Integrativa está de acordo com as atribuições propostas para ações de saúde mental na $A B$, o que valida e reafirma a importância de capacitar profissionais inseridos na ESF, uma vez que os benefícios também são coletivos, já que o próprio terapeuta vivencia uma mudança interna que reflete no profissional, repercutindo na sua relação com a comunidade. 


\section{CONSIDERAÇÕES FINAIS}

Ao término deste trabalho observamos como a $\mathrm{TCl}$ nos possibilita repensar o modo de agir diante dos conflitos e problemas. Por ser um instrumento do cuidado acessível aos profissionais para lidar com as situações de sofrimento psíquico, configura-se uma estratégia para assistir ao coletivo.

O processo de inserção da TCl na Atenção Básica por meio da ESF fomentou a necessidade de Pólos Formadores de Terapia Comunitária, que na Paraíba resultou na criação do MISC/PB, assumindo a responsabilidade de formar terapeutas comunitários sensíveis e comprometidos com a utilização dessa ferramenta do cuidado que ajuda a minimizar a dor e o sofrimento das pessoas na comunidade.

Ser terapeuta comunitário é mais do que fazer a $\mathrm{TCl}$. Antes de ser terapeuta, ele deve entender que quem faz a terapia é o coletivo que se dispõe a estar na roda. $O$ curso de formação em Terapia Comunitária Integrativa trabalha o autoconhecimento, a autoestima, segurança, paciência, entre outros pontos exigidos para que o terapeuta torne-se de fato capaz de coordenar uma roda de terapia com a distância necessária, evitando que suas relações e crises pessoais aflorem e o perturbem em contato com os casos apresentados.

Diante de todas as questões vislumbradas, confirmamos todos os benefícios que a terapia e o curso de formação trouxeram para a vida pessoal, o trabalho em equipe e com a comunidade, construindo um novo modo de pensar e agir. Os achados da pesquisa revelam a presença de uma transformação no processo de vida dos envolvidos, em que a melhora na autoestima se destaca a partir da confiança em si mesmo e em sua capacidade de superação. Avaliar o curso de formação em TCl oportuniza a continuidade das ações em saúde, ao nível da atenção básica, capacitando profissionais sensibilizados e engajados.

A visão panorâmica dos aspectos apresentados que envolvem os cursos de formação em TCl, possibilita um embasamento para ações estratégicas futuras e oportuniza novos trabalhos na área que visem, entre outros pontos, a continuidade das rodas de $\mathrm{TCl}$, de modo a evidenciar mecanismos para manutenção das mesmas.

\section{REFERÊNCIAS}

1. Organização Mundial da Saúde. Relatório sobre a saúde no mundo 2001 - Saúde mental: nova concepção, nova esperança. Suiça: OMS; 2001.

2. Nóbrega EM, Ferreira Filha MO. Estudos epidemiológicos na área de Saúde Mental realizados no Brasil. OBJN [Internet]. 2006 [cited 2011 jul 22]; 5(1):1-12. Available from: http://www.objnursing.uff.br/index.php/nursing/article/view/138. 3. Andrade FB, Bezerra AIC, Pontes ALF, Ferreira Filha MO, Vianna RPT, Dias MD, et al. Saúde mental na atenção básica: um estudo epidemiológico baseado no enfoque de risco. Rev. Bras. Enferm. 2009;62:675-80.

4. Andrade LOM, Barreto ICH, Barreto AP, Oliveira MVA. O SUS e a Terapia Comunitária. Fortaleza: Ministério da Saúde; 2008.

5. Rocha IA, Braga LAV, Tavares LM, Andrade FB, Ferreira Filha MO, Dias MD, et al. Terapia Comunitária como um novo instrumento de cuidado para a saúde mental do idoso. Rev. Bras. Enferm. 2009;62:695-700.

6. Barreto AP. Terapia Comunitária Passo a Passo. Fortaleza: LCR; 2008.

7. Ferreira Filha MO, Dias MD, Andrade FB, Lima EAR, Ribeiro FF, Silva MSS. A Terapia Comunitária como estratégia de promoção à saúde mental: o caminho para o empoderamento. Rev. Eletr. Enf. [Internet]. 2009 [cited 2011 jul 21]; 11(4):964-70. Avaible from: http://www.fen.ufg.br/revista/v11/n4/pdf/v11n4a22.pdf. 8. Barreto AP, Barreto MCR, Oliveira D, Barreto ICH, Abdala MP. Terapia Comunitária Integrativa na ESF/ SUS. Fortaleza: Ministério da Saúde; 2011.

9. Helder RR. Como fazer análise documental. Porto: Universidade de Algarve; 2006.

10. Bosi ML, Mercano FJ. Pesquisa qualitativa de serviços de saúde.

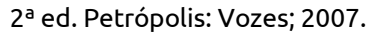

11. Campos CEA. O desafio da integralidade segundo as perspectivas da vigilância da saúde e da saúde da família. Ciênc. saúde coletiva [Internet]. 2003 [cited 2011 Jan 13]; 8(2):569-84. Available from: http://www.scielosp.org/scielo.php?script=sci arttext\&pid=S1413$81232003000200018 \&$ lng=pt.

12. Ceccarelli P. O sofrimento psíquico na perspectiva da psicopatologia fundamental. Psicol. estud. [Internet]. 2005 [cited 2011 jun 17]; 10(3):471-7. Available from: http://www.scielo.br/pdf/pe/v10n3/v10n3a14.pdf.

13. Souza GML, Silva PMC, Azevedo EB, Souza DS, Ferreira Filha MO. Influência da Terapia Comunitária na melhoria da qualidade de vida: percepção de seus participantes. In: $62^{\circ}$ Congresso Brasileiro de Enfermagem. 2010 out 11-15; Florianópolis, Brasil.

14. Pinto EB. Espiritualidade e religiosidade: articulações. Rev. Est. Religião. 2009;2004:68-83.

15. Boff L. Saber cuidar: ética do humano: compaixão pela terra. 7 ed. Petrópolis: Vozes; 2001.

16. Camarotti MH. Terapia Comunitária: Relato de experiência de implantação em Brasília - DF. In: I Congresso Brasileiro de Terapia Comunitária. 2003 mai 12-15; Ceará, Brasil. p. 60-76.

17. Cunha GT. A construção da clínica ampliada na atenção básica. São Paulo: Hucitec; 2005.

18. Oliveira AGB, Conciani ME, Marcon SR. A capacitação e a gestão de equipes do PSF para atenção psicossocial: um estudo de caso. Cienc. Cuid. Saude 2008;7(3):376-84.

19. Holanda VR, Dias MD, Ferreira Filha MO. Contribuições da terapia comunitária para o

enfrentamento das inquietações de gestantes. Rev. Eletr. Enf. [Internet]. 2007 [cited 2011 abr 23];9(1):79-92. Available from: http://www.fen.ufg.br/revista/v9/n1/v9n1a06.htm.

20. Reinaldo MAS. Saúde mental na atenção básica como processo histórico de evolução da psiquiatria comunitária. Esc. Anna Nery Rev. Enferm. 2008;12(1):173-8.

Artigo recebido em 18.09.2011.

Aprovado para publicação em 13.03.2012.

Artigo publicado em 30.03.2012 